\title{
ALAT KENDALI KECEPATAN MOTOR PADA PENGGERAK DEPAN SEPEDA LISTRIK DI POLITEKNIK NEGERI BATAM
}

\author{
Qoriatul Fitriyah, S.T., M.Sc. ${ }^{1}$, Renaldy Aritha ${ }^{1}$, Handri Toar ${ }^{1}$, Muhammad Prihadi Eko Wahyudi, S.T., \\ M.T. ${ }^{1}$ \\ * Politeknik Negeri Batam \\ Electrical Engineering Department Program \\ Jalan Ahmad Yani, Batam Centre, Batam 29461, Indonesia \\ E-mail: fitriyah@polibatam.ac.id.ac.id
}

\begin{abstract}
Abstrak
Motor Brushless DC (Motor BLDC) sudah banyak diaplikasikan diberbagai bidang industri, salah satunya di bidang transportasi. Pengoperasian motor BLDC memerlukan sistem kontrol kecepatan sebagai proses komutasinya dikarenakan motor ini tidak menggunakan sikat (brush). Penulis membuat kendali kecepatan motor brushless ini menggunakan arduino nano sebagai mikrokontroller untuk mengatur switching driver mosfet dengan tipe IR2103. Mosfet driver ini yang digunakan untuk mentrigger pensaklaran mosfet pada rangkaian inverter 3 fasa agar daya dari baterai dapat mengalir ke motor BLDC. Mosfet yang digunakan dalam inverter 3 fasa dengan tipe STP75NF75 dengan Vds 75 Volt dan Ids 80 Ampere dan jenis motor yang digunakan BLDC 350 Watt 36 Volt. Motor BLDC ini memiliki hall effect sensor sebagai pendeteksi posisi rotor. Untuk proses komutasi digunakan PWM sebagai nilai pulsa yang direpresentasikan untuk mengatur kecepatan motor dan frekuensi yang digunakan masih default dari pin Arduino. Kecepatan yang dihasilkan dari 224 - 340 rpm dengan konsumsi daya 20 Watt 21 Watt.
\end{abstract}

Kata kunci: Sepeda Listrik, Alat Kendali Kecepatan, PWM (Pulse Width Modulation), BLDC

\begin{abstract}
Brushless DC motor is applied in many field of industries, one of which transportation sector. The operation of BLDC motor need a speed control system as commutation process since it does not applied any brush. This research using an Arduino nano as its microcontroller to regulate the switching driver mosfet with IR2103 type. This mosfet driver is used to trigger mosfet switching at iverter 3 phase circuit so that power from battery can flow to BLDC motor. Mosfet type is STP75NF75 with Vds 75 Volt and Ids 80 Amps, while type of motor used is BLDC 350 watt and 36 Volt. The BLDC motor has Hall Effect sensor as rotor positioning detection. As for the commutation process, PWM is used as pulse modulation which is represented the motor speed and frequency of PIN default of Arduino. Speed earned is 224-340 rpm with power consumption of 20-21 Watts.
\end{abstract}

Keywords: Electric Bicycle, Speed Controller, PWM (Pulse Width Modulation), BLDC

\section{PENDAHULUAN}

Pada era sekarang teknologi sudah banyak berkembang untuk memenuhi kebutuhan manusia diberbagai bidang seperti transportasi, informasi dan komunikasi serta bidang lainnya. Pengembangan teknologi salah satunya ditujukan untuk mengoptimalkan penggunaan energi bahan bakar minyak (BBM) yang semakin menipis. Menurut BPS tahun 2015 penggunaan BBM jenis Premium mencapai 71733 barel [1]. Oleh karena itu dibutuhkan sumber energi alternatif untuk membantu mengatasi krisis energi.

Salah satu bentuk energi adalah energi listrik. Energi listrik adalah energi pembawa yang penggunaannya saat luas. Energi ini hampir digunakan pada setiap kegiatan manusia, mulai dari pemakaian industri, rumah tangga, pertanian, dan 
komersial untuk menggerakkan peralatan mesin, penerangan, dan pemanasan [2]. Oleh karena itu di bidang transportasi dilakukan pembuatan sepeda listrik. Sepeda listrik ialah transportasi darat yang ramah lingkungan tanpa polusi udara. Sepeda listrik didesain menggunakan motor DC tanpa sikat (brushless), pengendali kecepatan motor dengan mengatur sinyal PWM (Pulse Width Modulation) sehingga sepeda listrik mampu dikendarai secara lambat maupun cepat, serta menggunakan baterai sebagai penyimpanan daya untuk menggerakkan motor. Di Politeknik Negeri Batam, sepeda listrik berfungsi sebagai bahan penelitian serta mampu menjadi transportasi yang santai.

\section{DASAR TEORI}

\subsection{Motor Brushless DC}

Motor Brushless DC merupakan mesin penggerak bertenaga listrik yang populer karena memiliki kelebihan dibanding dengan jenis mesin penggerak bertenaga listrik lainnya. Kelebihan motor BLDC adalah dimensi motor lebih kecil daripada motor DC konvensional, efisiensi lebih besar daripada motor induksi. Dengan tidak adanya sikat, perawatan menjadi ringan hampir tidak ada noise. Tanggapan motor BLDC lebih cepat, umur pemakaian lebih lama dan mempunyai rentang kecepatan yang lebar [3].

Motor BLDC perlu diatur kecepatannya sesuai dengan tanggapan yang diharapkan berdasarkan kegunaanya diberbagai bidang seperti industri otomotif, kesehatan, transportasi, otomasi industri dan instrumentasi [3]. Bagian - bagian dari motor brushless DC, antara lain:

\subsubsection{Stator}

Stator dari motor BLDC menyerupai dengan motor induksi. Tetapi lilitannya dibuat berbeda. Motor BLDC mempunyai tiga gulungan stator dihubungkan secara bintang [4].

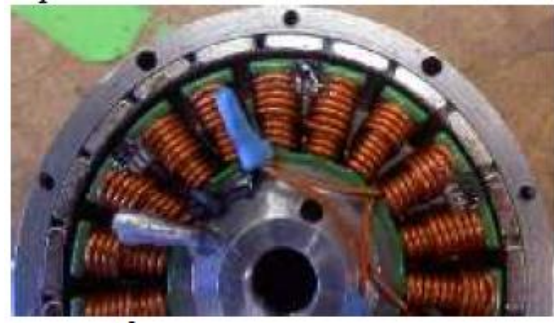

Gambar 1. Stator [5]

\subsubsection{Rotor}

Rotor adalah bagian dari motor yang berputar karena adanya gaya elektromagnetik dari stator. Rotor pada motor BLDC hanya tersusun dari satu buah elektromagnet yang berada diantara brushless (sikat) [4].

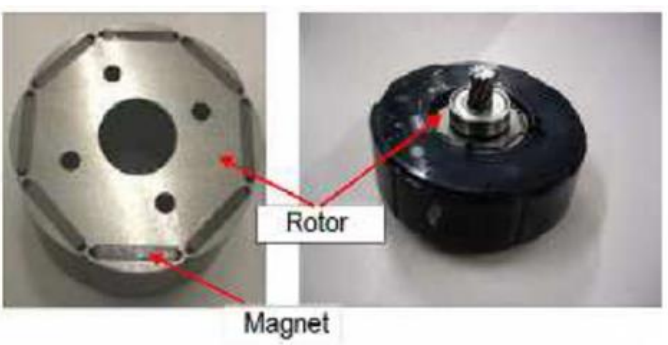

Gambar 2. Rotor [5]

\subsubsection{Hall Sensor}

Komutasi motor brushless DC ini diatur secara elektronik agar motor dapat berputar. Hall sensor ini sebagai pendeteksi pada bagian rotor yang ter-energize oleh fluks magnet sehingga proses komutasi yang berbeda (enam step) dapat dilakukan oleh stator dengan tepat karna hall sensor ini menempel pada bagian stator motor [5].

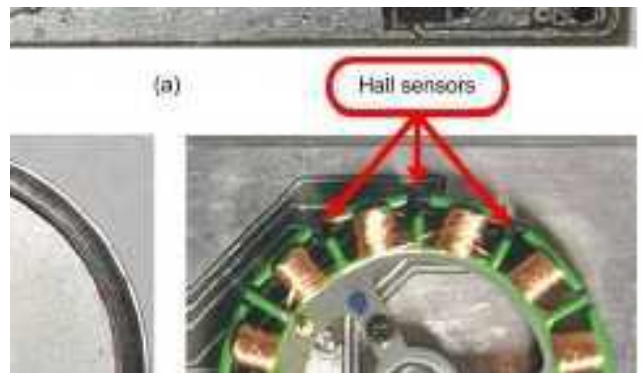

Gambar 3. Hall Sensor [5]

\subsubsection{Prinsip Kerja Motor Brushless DC}

Prinsip kerja motor BLDC sebenarnya sama dengan motor DC konvensional namun berbeda pada proses komutasinya. Motor BLDC menggunakan teknologi elektronik dalam proses komutasinya, yaitu sensor Hall dan kontroler [7]. 
Untuk lebih jelasnya dapat dilihat dari Gambar 4.

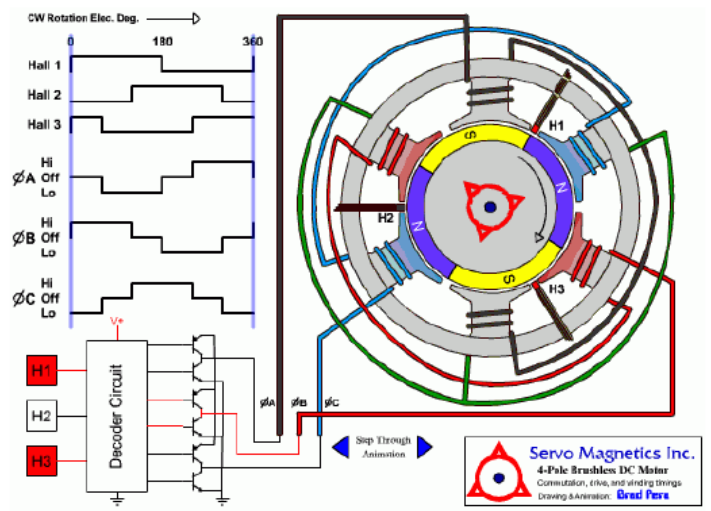

\section{Gambar 4. Skema Kerja Motor BLDC[7]}

Pertama, hall sensor $\mathrm{H} 1$ dan $\mathrm{H} 3$ bernilai 1 karena mengalami perubahan medan magnet. Sehingga kontroler mengalirkan arus pada lilitan B dan C. Lilitan B menjadi kutub utara dan lilitan C menjadi kutub selatan. Kutub utara oleh lilitan B memberikan tolakan pada kutub utara magnet rotor, sedangkan kutub selatan lilitan $\mathrm{C}$ menarik kutub utara magnet rotor.

Langkah kedua, hanya sensor H1 yang bernilai "high", sehingga kontroler akan menginstruksikan agar lilitan A dan B harus dialiri arus. Lilitan A menghasilkan kutub selatan dan lilitan B tetap menghasilkan kutub utara. Kutub selatan lilitan A akan menolak kutub selatan pada magnet rotor. Sedangkan kutub utara lilitan B menolak kutub utara dari magnet rotor.

Langkah ketiga, sensor $\mathrm{H} 1$ dan $\mathrm{H} 2$ bernilai 1. Sehingga kontroler menginstruksikan agar lilitan A dan $\mathrm{C}$ dialiri arus. Lilitan A tetap menghasilkan kutub selatan dan lilitan C menghasilkan kutub utara. Kutub selatan lilitan A akan menolak kutub selatan dan menarik kutub utara pada magnet rotor. Sedangkan kutub utara lilitan C menarik kutub selatan dari magnet rotor.

Langkah keempat, hanya sensor $\mathrm{H} 2$ yang bernilai 1. Sehingga kontroler menginstruksikan agar lilitan B dan C dialiri arus. Lilitan B menghasilkan kutub selatan dan lilitan $\mathrm{C}$ tetap menghasilkan kutub utara. Kutub selatan lilitan B menolak kutub selatan pada magnet rotor. Sedangkan kutub utara lilitan C menarik kutub selatan dari magnet rotor.

Langkah kelima, sensor H2 dan H3 bernilai 1.
Sehingga kontroler menginstruksikan agar lilitan A dan B dialiri arus. Lilitan A menghasilkan kutub utara dan lilitan B tetap menghasilkan kutub selatan. Kutub utara lilitan A akan menolak kutub utara dan menarik kutub selatan pada magnet rotor. Sedangkan kutub selatan lilitan B menolak kutub selatan dari magnet rotor.

Langkah keenam atau terakhir pada siklus komutasi, hanya sensor H3 yang bernilai 1. Sehingga kontroler menginstruksikan agar lilitan A dan C dialiri arus. Lilitan A tetap menghasilkan kutub utara dan lilitan C menghasilkan kutub selatan. Kutub utara lilitan A akan menarik kutub selatan dan menolak kutub utara pada magnet rotor. Sedangkan kutub selatan lilitan $\mathrm{C}$ menarik kutub utara dari magnet rotor.

Keenam proses di atas mengalami pengulangan hingga membentuk suatu siklus. Hal inilah yang menyebabkan motor terus berputar secara kontinyu selama sumber arus DC masih ada [7].

\section{RANCANGAN SISTEM}

\subsection{Rancangan Penelitian}

Rancangan atau tahapan penelitian untuk menjawab perumusan masalah dari tugas akhir ini adalah sebagai berikut:

1. Studi Literatur.

2. Penentuan spesifikasi komponen.

3. Perancangan kontroler dan inverter.

4. Pengujian kontroller dan inverter.

5. Analisis data dari hasil pengujian sistem.

6. Evaluasi hasil pengujian serta perbaikan sistem.

7. Penulisan laporan hasil analisa dan pembahasan.

Tahapan penelitian ini ditunjukkan dalam Gambar 5. 


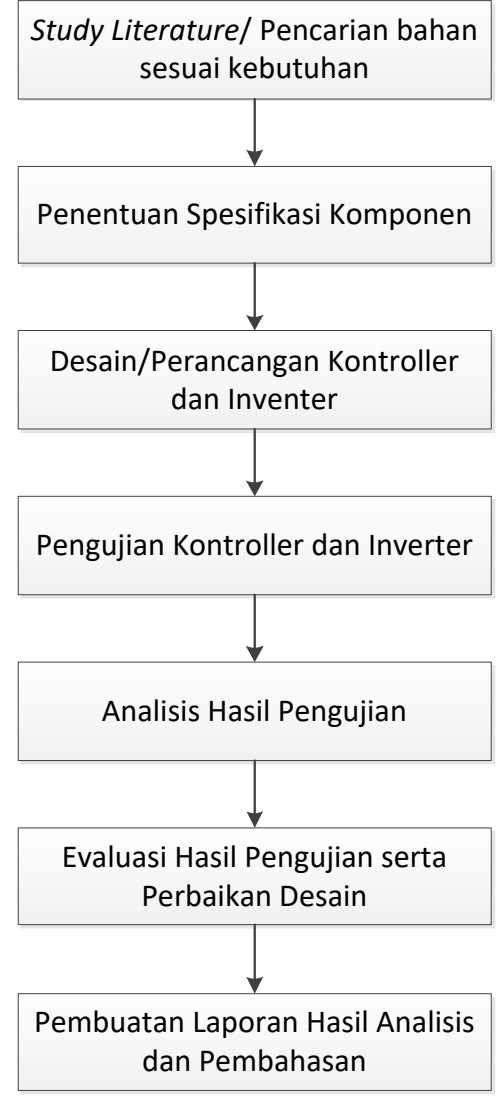

Gambar 5. Rancangan Penelitian

\section{HASIL DAN PEMBAHASAN}

\subsection{Spesifikasi Motor yang Digunakan}

Motor listrik yang digunakan adalah motor brushless sensored dengan spesifikasi:

- Tegangan : 36 Volt

- Daya : 350 Watt

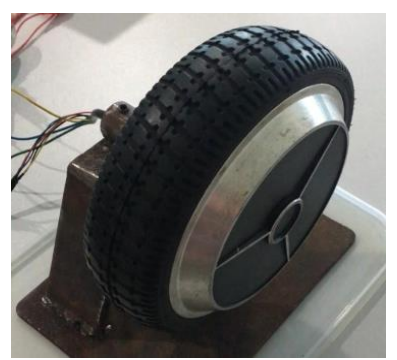

Gambar 6. Motor Brushless DC 36V/350W

\subsection{Rancangan Perangkat Keras}

Perangkat keras yang digunakan pada penelitian ini dapat ditunjukkan, sebagai berikut:

\subsubsection{Sistem Kerja Perangkat Keras}

Dari komponen yang sudah dijabarkan berikut perangkat keras yang digunakan pada penelitian ini dapat ditunjukkan pada Gambar 7, sebagai berikut:

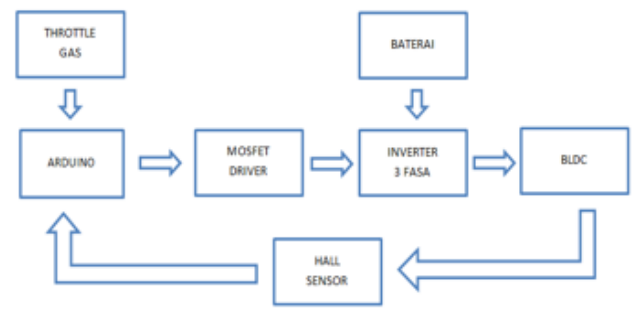

Gambar 7. Sistem Kerja Perangkat Keras

Throttle gas bekerja sebagai input arduino untuk selanjutnya dikirim ke mosfet driver yang menggerakkan inverter 3 fasa dengan bantuan baterai dan menjalankan motor BLDC. BLDC akan mengirimkan sinyal melalui hall sensor yang diterima kembali oleh arduino.

\subsubsection{Perancangan Mosfet Driver}

Untuk membantu proses pensaklaran mosfet yang ditrigger dari pin PWM arduino dibutuhkan rangkaian kendali mosfet. Penulis menggunakan IC tipe IR2103 sebagai pengendali pensaklaran dua buah mosfet yang dibutuhkan inverter 3 fasa. Spesifikasi dari IR2103, sebagai berikut:
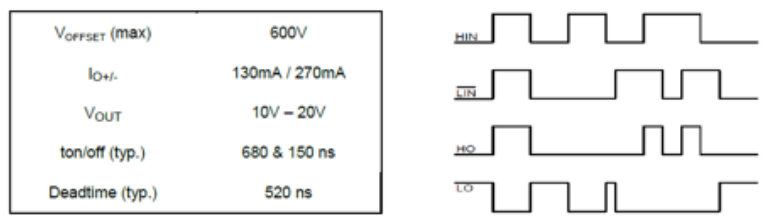

\section{Gambar 8. Spesifikasi IR2103}

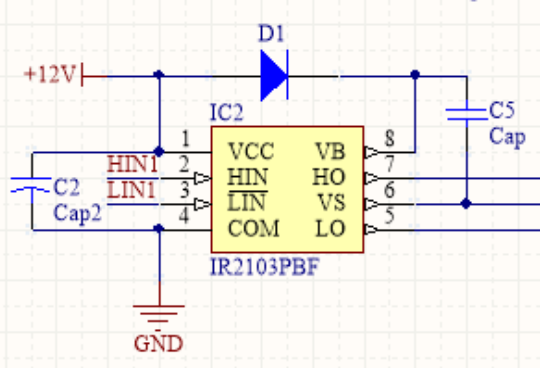

Gambar 9. Skematik Mosfet Driver

Pada Gambar 9 dapat dilihat perancangan mosfet driver sebagai trigger mosfet yang on dan off. VCC digunakan 12 volt dan ditambahkan dioda fast switching tipe IN4002 ke pin VB. Pin HIN dihubungkan ke pin PWM arduino untuk mengaktifkan mosfet high side. Sedangkan pin LIN dihubungkan ke pin digital arduino untuk mengaktifkan mosfet low side. C2 digunakan untuk 
filter 12 volt dan C5 digunakan sebagai bootstrap untuk pin $\mathrm{HO}$.

\subsubsection{Inverter 3 Fasa}

Untuk membangkitkan daya yang mengalir ke motor BLDC dapat dilihat pada Gambar 14.

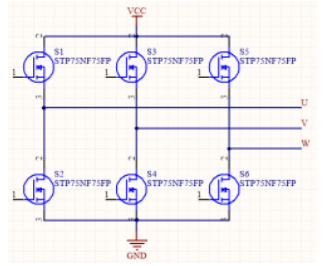

\section{Gambar 9. Skematik Inverter 3 Fasa}

Agar motor brushless berputar dibutuhkan 6 kondisi pensaklaran dari inverter. Proses pensaklaran, sebagai berikut:

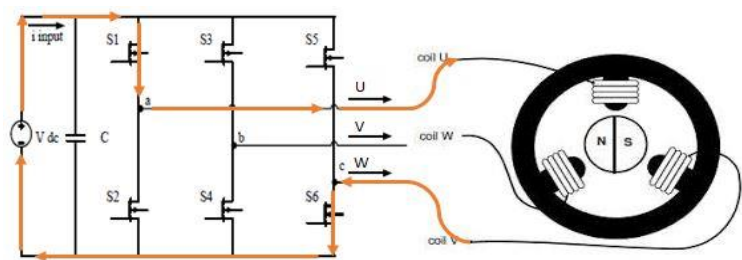

Gambar 10. Pensaklaran Step 1

Pada step 1, saat kondisi hall sensor bernilai 100 maka S1 dan S6 akan aktif. Arus positif mengalir melalui S1 menuju koil U dan keluar dari koil W melalui S6 menuju arus negatif. Motor akan berputar 60 derajat searah jarum jam.

4.2.4 Pengujian Kecepatan Motor dan

\section{Konsumsi Daya}

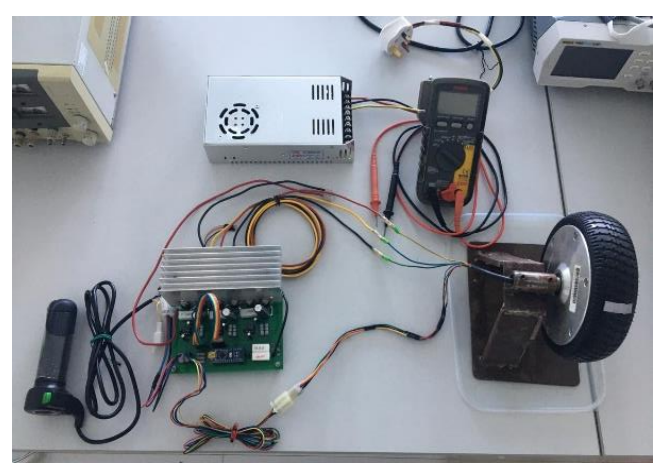

Gambar 11. Komponen yang Digunakan

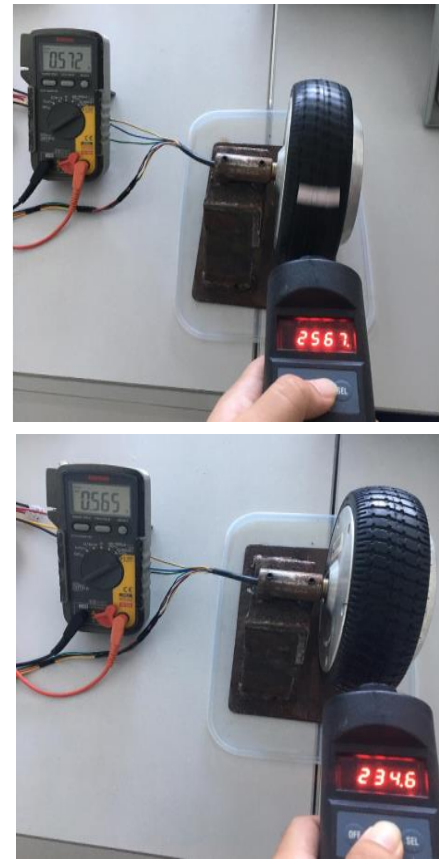

Gambar 12. Pengukuran Kecepatan Menggunakan Tachometer

Dalam pengujian kecepatan yang dilakukan penulis mengatur kecepatan menggunakan throttle gas dan didapatkan beberapa data kecepatan dengan kondisi motor tanpa beban. Berikut hasil pengujian:

Tabel 1. Hasil Pengujian Kecepatan Motor

\begin{tabular}{|l|c|c|}
\hline No & Throttle Gas \% & Kecepatan (rpm) \\
\hline 1. & 0 & 0 \\
\hline 2. & 25 & 234.6 \\
\hline 3. & 50 & 256.7 \\
\hline 4. & 75 & 281.3 \\
\hline 5. & 95 & 303.2 \\
\hline
\end{tabular}

Dari data yang ditampilkan dapat terlihat kenaikan kecepatan dari motor dengan kondisi trottler gas berbanding lurus. Apabila throttle di gas $25 \%$ maka kecepatan motor $234.6 \mathrm{rpm}$, gas $50 \%$ kecepatan motor 256.7, gas $75 \%$ kecepatan motor 281.3 dan gas $95 \%$ maka kecepatan motor 303.2 rpm.

\section{KESIMPULAN}

Dari hasil pengujian, didapatkan kenaikan kecepatan dari motor yang berbanding lurus dengan kondisi throttle gas. Apabila throttle di gas $25 \%$ maka kecepatan motor 234,6 rpm. Sedangkan saat di gas $95 \%$ maka kecepatan motor 303,2 rpm 


\section{REFERENCES}

[1] Badan Pusat Statistik. Internet: https://www.bps.go.id/dynamictable/2016/0 1/28/1125/produksi-bahan-bakar-minyak-bb m-1996-2015.html [14 Feb 2019].

[2] International Energy Agency. Internet: https://www.iea.org/publications/freepublic ations/pu

[3] blication/statistics_manual_indonesian.pdf [14 Feb 2019].

[4] Agung Dwi Yulianta, Sasongko Pramono Hadi, Suharyanto, "Pengendalian Kecepatan Motor Brushless DC (BLDC) menggunakan Metode Logika Fuzzy", Jurnal Sains, Teknologi dan Industri, Vol. 12, No. 2, Juni 2015, pp. $248-254$.

[5] Fauzan Rahman, "PENINGKATAN KINERJA PENGEREMAN MOTOR BLDC PADA SEPEDA LISTRIK BERBASIS LOGIKA FUZZY". Internet: http://ejurnal.bunghatta.ac.id/index.php?jour nal $=J$ FTI\&page $=$ article \&op $=$ view $\&$ path $\% 5$ B \%5D=10352\&path\%5B\%5D=8648， 2017 [10 Februari 2019].

[6] Nanang Masudi. "DESAIN CONTROLLER MOTOR BLDC UNTUK MENINGKATKAN PERFORMA (DAYA OUTPUT) SEPEDA MOTOR LISTRIK". Institut Teknologi Sepuluh Nopember, Surabaya, 2014.

[7] Benhur Nainggolan, Fadhilla Inaswara, Gilang Pratiwi dan Hirzan Ramadhan. "RANCANG BANGUN SEPEDA LISTRIK MENGGUNAKAN PANEL SURYA SEBAGAI PENGISI BATERAI". POLITEKNOLOGI VOL. 15 No. 3 SEPTEMBER 2016, pp.263-272. 